\title{
Bird and mammal conservation in Gaoligongshan Region and Jingdong County, Yunnan, China: patterns of species richness and nature reserves
}

\author{
Daoying Lan and Robin Dunbar
}

\begin{abstract}
Elevational and latitudinal patterns of species richness for birds and mammals were compared with human population density in relation to nature reserve designation in two areas of Yunnan Province, China. Results suggest that species richness is not the same for the two areas. In Gaoligongshan Region, species richness is inversely correlated with elevation and altitude, while reserve designation is positively correlated with elevation and latitude. In Jingdong County, reserve designations are positively correlated with elevation, but species richness shows no clear trends. In general, the present situation is strongly influenced by human activities. It appears that reserve designation is
\end{abstract}

mismatched with species richness in Gaoligongshan Region, while there is a better fit between the two in Jingdong County. In both areas, however, it appeared that reserves were located primarily in order to reduce conflict with humans rather than to maximize conservation of biodiversity, probably because humans were responsible for forest-especially primary forest-destruction and degradation in the low-lying areas.

Keywords Biodiversity, birds, China, human density, mammals, nature reserves, species richness, Yunnan Province.

\section{Introduction}

Conservation of biological diversity has become an issue of great debate, and a topic of concern worldwide. In particular, the conservation of biodiversity in tropical forests has aroused much concern, making such areas the 'hot spots' within a hot topic (McNeely, 1990). Situated in south-west China, Yunnan Province constitutes one such hot spot. The area is one of the most biologically diverse in China (Zhang \& Lin, 1985), and arguably the world (Wang \& Wang, 1990). Within Yunnan, Gaoligongshan Region and Jingdong County are the most outstanding in terms of biodiversity, and have been the subject of great concern by conservation biologists.

In response to the increased need to conserve biodiversity, China has rapidly expanded its system of nature reserves since the $1980 \mathrm{~s}$ ( $\mathrm{Li} \&$ Zhao, 1989). In Gaoligongshan Region, three reserves have been established (one at the national level and two at the provincial level), encompassing c. 13.5 percent of the total

Daoying Lan (corresponding author) Kunming Institute of Zoology, Chinese Academy of Sciences, Kunming, Yunnan, China \& School of Biological Sciences, University of Liverpool, Nicholson Building, Liverpool L69 3GS, UK. E-mail: daoying@liv.ac.uk or jdylan@public.km.yn.cn

Robin Dunbar School of Biological Sciences, University of Liverpool, Nicholson Building, Liverpool L69 3GS, UK.

Revised manuscript accepted for publication 5 June 2000 land area $(27,981 \mathrm{sq} \mathrm{km})$. In Jingdong County, two reserves have been established (one at the national level and one at the provincial level), encompassing c. 7.8 percent of the total land area $(4465.85 \mathrm{sq} \mathrm{km})$. Designation of all these nature reserves was carried out in the early 1980s (No. 5 Forest Resources Survey Team of Yunnan Province, 1983; Forestry Planning and Surveying Institute of Yunnan Province, 1989).

The management of these reserves has been problematic; this issue is treated in more depth by other publications (see, for example, Ma et al., 1994, 1995, 1997; Lan et al., 1995 [Gaoligongshan]; Wuliangshan Mountain Reserve Management Bureau, 1994; Lan, 1995a,b [Jingdong County, Mt. Wuliangshan and Mt. Ailaoshan]). In this paper, we address a different concern: how well do current reserve boundaries correspond with the requirements of biodiversity conservation? More specifically, we examine how reserve areas correspond with documented species richness for birds and mammals. We selected Gaoligongshan Region and Jingdong County as case studies not only because they are important in terms of Yunnan's wildlife conservation, but also because the data available for these areas are more complete.

\section{Study areas}

\section{Gaoligongshan Region}

The region referred to as Gaoligongshan here includes all lands west of the Salween (Nujiang) River in 
Yunnan. The entire region is situated at the southern edge of the eastern Himalayas, the westernmost region of Yunnan Province, and in the western part of the Trans-Himalayan Mountains. The geographic coordinates for this region are c. $23^{\circ} 50^{\prime}-28^{\circ} 30^{\prime} \mathrm{N}, 97^{\circ} 31^{\prime}-$ $99^{\circ} 05^{\prime} \mathrm{E}$ (Fig. 1).

In accordance with its complex topography and extreme elevational gradients $(210-5128 \mathrm{~m})$, the bioclimatic conditions of Gaoligongshan Region are wide ranging, from the cold Tibetan Plateau in the north to tropical rain forest in the south. The region forms a link between very different biotic realms, with species of both the Oriental and Palaearctic communities being represented. There are also many endemic and rare species (Wu et al., 1979; Zhang, 1979; Zheng et al., 1981).

Three nature reserves established to protect these varied natural resources are, from north to south:

i) Nujiang (provincial level) Nature Reserve, established in 1986, principally to protect temperate and cold forest ecosystems and associated rare species such as the takin Budorcas taxicolor, pileated langur Trachypi- thecus pileatus and Sclater's monal Lophophorus sclateri. This reserve is divided into two sections of $2376 \mathrm{sq} \mathrm{km}$ (northern section) and $415 \mathrm{sq} \mathrm{km}$ (southern section), respectively, totalling $2791 \mathrm{sq} \mathrm{km}$. For the northern section, only the part to the west of the Salween River $(1767 \mathrm{sq} \mathrm{km})$ is included in the present analysis.

ii) Gaoligongshan (national level) Nature Reserve $(1240 \mathrm{sq} \mathrm{km})$ was established in 1983, mainly to protect subtropical forest ecosystems and rare species such as the hoolock gibbon Hylobates hoolock, red panda Ailurus fulgens and Temminck's tragopan Tragopan temminckii.

iii) Tongbiguan (provincial level) Nature Reserve, established in 1986, primarily to protect tropical forest ecosystems and species such as binturong Arcticis binturong, gaur Bos gaurus and peacock pheasant Polyplectron bicalcaratum. This reserve is made up of three sections of 260,23 and $71 \mathrm{sq} \mathrm{km}$, respectively (total $354 \mathrm{sq} \mathrm{km}$ ). The location of these protected areas is shown in Fig. 1.

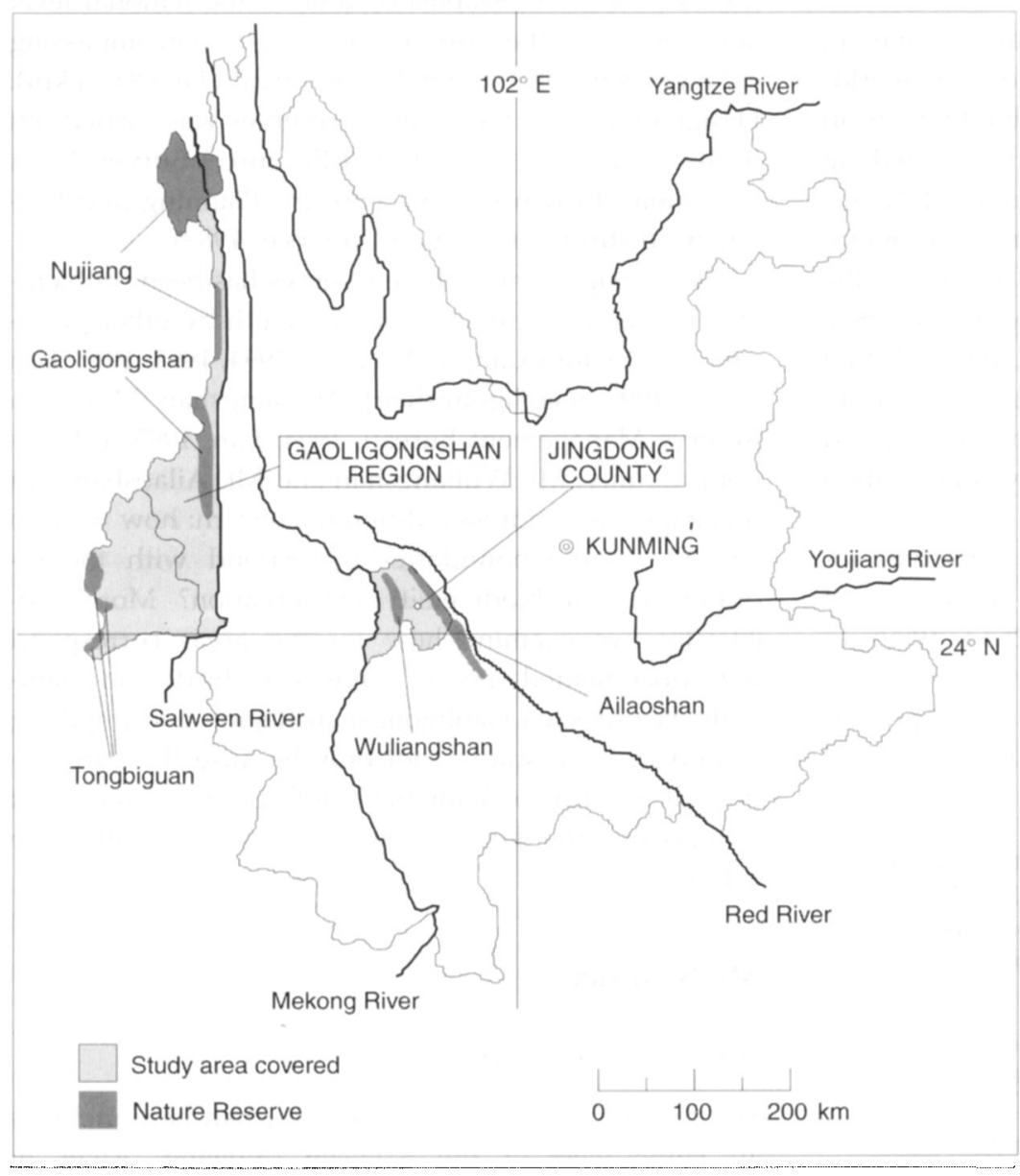

Fig. 1 Map of Yunnan Province, China. Gaoligongshan Region (west) and Jingdong County (central) are indicated by shading. 


\section{Jingdong County}

Jingdong County is located to the east of the Mekong (Lancangiiang) River in central Yunnan. The entire region is situated at the southern edge of the eastern Himalayas, in the south-central region of Yunnan. The geographic coordinates for this region are c. $23^{\circ} 57^{\prime}-$ $24^{\circ} 50^{\prime} \mathrm{N}, 100^{\circ} 24^{\prime}-101^{\circ} 15^{\prime} \mathrm{E}$ (Fig. 1).

Jingdong County also has a complex topography, extreme elevational gradients (795-3372 m) and contrasting climatic conditions (temperate to tropical). Below $1300 \mathrm{~m}$ altitude, the land has generally been cultivated for agriculture, with only a few areas of dry and hot riverbed savanna vegetation remaining. Between 1300 and $1800 \mathrm{~m}$, the vegetation is generally pine forest (Pinus kesiya var. langbianensis); in some valleys, deteriorated leaf forest remains following considerable human disturbance. From 1800 to $2400 \mathrm{~m}$, the forest is mostly monsoon broadleaf forest, although some parts have been converted into pine forest by human activity. Mid-montane humid evergreen broadleaf forest dominates from 2400 to $3000 \mathrm{~m}$. Above $3000 \mathrm{~m}$, only shrub and herb vegetation are found. Jingdong County also forms a link between two different biotic realms (Oriental and Palaearctic). There are many endemic and rare species (Liu et al., 1994; Peng, 1997).

In this county, two nature reserves have been established to protect biodiversity. They are, from west to east:

i) Wuliangshan (provincial level) Nature Reserve (234 sq km), established in 1986, primarily to protect temperate and cold forest ecosystems and associated rare species such as the black gibbon Hylobates concolor and Phayre's langur Trachypithecus phayrei.

ii) Ailaoshan (national level) Nature Reserve, established in 1986, principally to protect the subtropical forest ecosystem and rare species such as the black gibbon, Phayre's langur, red panda and Temminck's tragopan Tragopan temminckii. Part of the Ailaoshan Nature Reserve lies outside Jingdong County in the counties of Zhengyuan, Xinping, Shuangbai and Chuxiong. The total area for this nature reserve is $504 \mathrm{sq} \mathrm{km}$. Only the part within Jingdong County (116 sq km) has been included in the analysis in this paper. The area of the two reserves combined $(350 \mathrm{sq} \mathrm{km}$ ) represents 7.85 per cent of Jingdong County.

\section{Methods}

Estimates of total land area, human population density and area currently provided Nature Reserve status, stratified by elevational bands (at intervals of $500-\mathrm{m}$ altitude) were calculated. For Gaoligongshan Region, we also stratified the land by latitudinal bands (roughly $1^{\circ}$ ). Our general approach followed Hunter \& Yonzon (1993).

In each case, the figure for human population is that which pertained at the time the nature reserve was designated, rather than the current population size because our concern is with the factors that influenced the decisions of the planners when they established the reserves. The data are for 1978 and 1984 for Gaoligongshan Region and Jingdong County, respectively. Based on interviews with local officials and villagers, we found that the distributions of villages and the human population altered little prior to the early 1980s. Although significant changes occurred thereafter, these changes were limited to increases in the size of the population, not to the establishment of new villages. Furthermore, most of the population increase over the last two decades has been confined to the major low altitude urban centres.

Data on mammals and birds were based on the specimens in the collections of the Kunming Institute of Zoology up to 1994. Those specimens were collected mainly during surveys prior to the 1980 s, and reflect the original fauna when the nature reserves were designated (e.g. Bird Group of Kunming Institute of Zoology, 1980, for birds). One of the surveys used was carried out between 1992 and 1994, but the results mainly clarified the original distribution of those species among the elevational bands, rather than yielding many new species. Although we have not listed the species involved (the combined examples contain about 300 bird species and 90 mammal species), full species lists can be obtained from the corresponding author.

\section{Gaoligongshan Region}

Total land area was calculated by adding up the area of each of the 13 counties within the region (Yunnan Mapping Bureau, 1982). We defined Gaoligongshan Region as only those areas west of the Salween River. However, because some counties are located on both sides of the Salween River, we first determined the proportion of each county on each side of the river (digitized from county topographic maps and calculated using AUTOCAD 11.0), and included the western section only in the calculations. Total human population was assumed to be uniform within each county.

To estimate the proportion of area within each latitudinal and elevational band, we first overlaid each county topographic map with an acetate grid, and counted the number of grid intersections within each band. The total area within each band was then computed by multiplying the published county total by the proportion of total intersections falling within each band. Nature reserve boundaries (Forestry Planning 
and Surveying Institute of Yunnan Province, 1989) were then plotted onto the county topographic maps, and all steps described above were repeated for areas within the plotted boundaries.

Departing somewhat from the procedures of Hunter \& Yonzon (1993), human population density was estimated by tallying the total number of towns on county topographic maps falling within each elevational and latitudinal band $(n=1620)$. The 13 county seats (mean population $=9600$ ) were assumed to equal five towns each for the purposes of this estimation. The population within each band was then calculated by multiplying the published county total by the proportional distribution of towns.

Total species richness of all avian and mammalian species was calculated (including, within Mammalia, the orders Artiodactyla, Carnivora and Primates) (Ma et al., 1994). We examined locational records for 2523 mammal specimens (totalling 178 species through 1994) and 3130 bird specimens (totalling 487 species through 1993). Each species was classified as belonging to one or more latitudinal and elevational bands using the minimum and maximum recorded latitude and elevation of all specimens.

\section{Jingdong County}

Similar methods were applied to Jingdong County. However, because data about vegetation types and climatic zones are clearly defined for the county, we divided the land surface into five elevational strata, in accordance with the vegetation types and climatic zones.

Once again, we counted the altitudinal distribution of total land and nature reserve land by overlaying acetate grids on 1:50,000 maps of Jingdong County. We checked the altitude of each intersection of the grid $(1 \times 1 \mathrm{sq} \mathrm{km}$ for nature reserve, with $3 \times 3 \mathrm{sq} \mathrm{km}$ for the total land area). In addition, we counted the number of intersections within each altitudinal stratum. The area within each stratum was then computed by multiplying the total area of the county by the proportion of intersections landing within each stratum.

On the map of Jingdong, a total of 341 points was checked for the nature reserves and 603 points for the total county. The actual area above $3000 \mathrm{~m}$, calculated from the $1: 50,000 \mathrm{map}$, was about $11 \mathrm{sq} \mathrm{km}$. We determined the human density by adding up the human population figures according to the altitude of each administrative village centre (Committee of Annals Compiling of Jingdong County, 1994). The population data for each village are based on a survey conducted in 1984 (Forestry Zonation Office of Jingdong County, 1986).
Species richness of avian and mammalian species (including, within Mammalia, the orders Artiodactyla, Carnivora and Primates) is based on Wang et al. (1994) and Yang et al. (1994). A total of 101 mammal species and 296 avian species were classified into different elevational strata. Both Wang et al. (1994) and Yang et $a l$. (1994) provide detailed tables that classify the distribution of each species in different habitats at different altitudes and include good descriptions about the distribution. We also used numbers of protected mammal and bird species from the same sources for analysis.

Standard correlation and linear regression analyses were run to deduce trends. Proportions were normalized using arc-sine transformation, and significance was taken as $P<0.05$, unless otherwise specified.

\section{Results}

\section{Gaoligongshan Region}

Total area, population and the extent of the area protected by reserves are shown in Table 1 . Table 2 illustrates area and species richness by elevational bands, and Table 3 presents a comparison of area protected and human population density analysed by latitude.

\section{Patterns in species richness}

For mammal species, 36 and 71 per cent of all recorded species were found in the $0-500$ and 2000$3000 \mathrm{~m}$ strata, respectively. For birds, 68 per cent of all recorded species occurred below $2500 \mathrm{~m}$ and 59 per cent occurred within the narrow $1000-1500 \mathrm{~m}$ stratum.

Fifty-four avian (11.1 per cent) and 63 mammalian species ( 35.4 per cent) were recorded in the lowest elevational band (210-500 $\mathrm{m}$ ) despite the fact that it accounts for less than 0.3 percent of the region's total area. Species richness in the highest elevations appeared to be much lower, but may have been underestimated if proportionately fewer specimens were collected in these inaccessible areas.

Patterns of species richness by latitudinal strata were less clear (in part because data were unavailable for the $26-27^{\circ}$ strata, conditions for sampling in this region being so difficult that few surveys had been conducted). It appeared that bird species richness decreased with latitude, although mammals showed a less clear pattern.

Both elevational and latitudinal patterns suggested a similar underlying dynamic, particularly for birds: species richness tended to be higher in tropical and sub-tropical areas, and lower in the simpler forest types at higher elevations (which, in Gaoligongshan Region, were themselves correlated with higher latitudes). We 


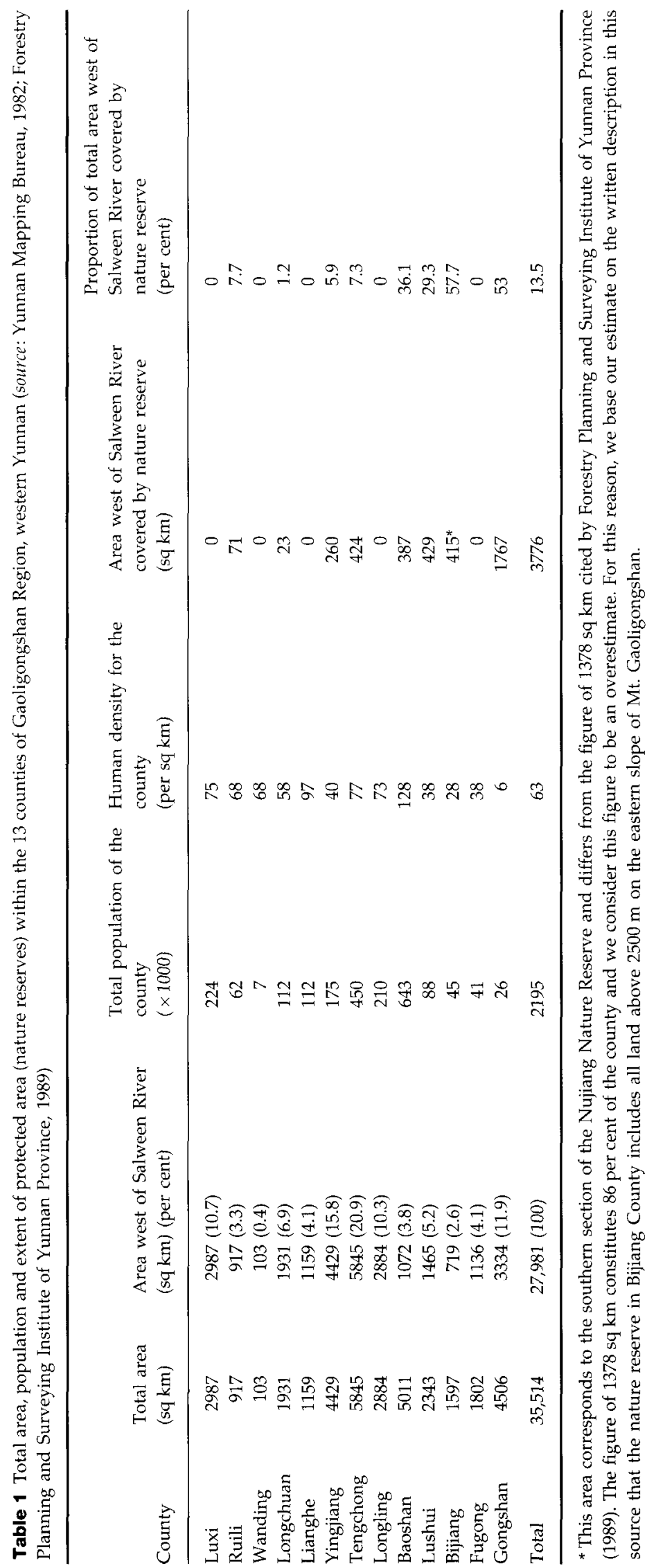


did not sample other taxa, but Hunter \& Yonzon (1993) suggested that, at least in Nepal, which is topographically similar, amphibians, reptiles and fish show similar trends.

\section{Reserve location}

How well did existing reserves, stratified by elevation and latitude, correspond with the patterns of species richness? Contrary to the ideal strategy - from the per- spective of biodiversity conservation - the proportion of total land in reserves showed a negative, rather than positive, correlation with species richness (Fig. 2). For example, stratified by elevation, the proportion of land in reserves was negatively correlated with total mammalian richness $(r=-0.685, P=0.029)$, avian richness $(r=-0.973, P<0.0001)$, as well as number of carnivore $(r=-0.759, P=0.019)$ and primate $(r=-0.843$, $P<0.0001)$ species, although the correlation with the

Table 2 Total area, area under nature reserve designation, species richness and human population density in Gaoligongshan Region, stratified by elevational band

\begin{tabular}{|c|c|c|c|c|c|}
\hline $\begin{array}{l}\text { Elevation } \\
(\times 100 \mathrm{~m})\end{array}$ & $\begin{array}{l}\text { Total area } \\
(\mathrm{sq} \mathrm{km})\end{array}$ & $\begin{array}{l}\text { Reserve area } \\
(\mathrm{sq} \mathrm{km})\end{array}$ & $\begin{array}{l}\text { Bird species number in the } \\
\text { whole area }\end{array}$ & $\begin{array}{l}\text { Mammal species in the } \\
\text { whole area }\end{array}$ & $\begin{array}{l}\text { Human density } \\
\text { (per sq } \mathrm{km} \text { ) }\end{array}$ \\
\hline $2.1-5$ & 73 & 24 & 54 & 63 & 55 \\
\hline $5-10$ & 3316 & 106 & 245 & 94 & 104 \\
\hline $10-15$ & 5987 & 140 & 289 & 100 & 72 \\
\hline $15-20$ & 7734 & 201 & 235 & 104 & 89 \\
\hline $20-25$ & 5369 & 582 & 194 & 112 & 24 \\
\hline $25-30$ & 2223 & 988 & 95 & 111 & 0 \\
\hline $30-35$ & 1733 & 901 & 51 & 95 & 0 \\
\hline $35-40$ & 1279 & 678 & 1 & 49 & 0 \\
\hline $40-45$ & 204 & 117 & 0 & 31 & 0 \\
\hline$>45$ & 63 & 39 & 0 & 16 & 0 \\
\hline Total (average) & 27,981 & 3776 & 487 & 178 & $(58)$ \\
\hline
\end{tabular}

For details of calculation, see text.

Table 3 Total area west of the Salween River, total area under nature reserve designation, and proportion of total area protected, by latitudinal bands, Gaoligongshan Region, western Yunnan

\begin{tabular}{lcccc}
\hline Latitude band & $\begin{array}{l}\text { Total area } \\
(\mathrm{sq} \mathrm{km})\end{array}$ & $\begin{array}{l}\text { Protected area } \\
(\mathrm{sq} \mathrm{km})\end{array}$ & $\begin{array}{l}\text { Proportion protected } \\
\text { (per cent) }\end{array}$ & $\begin{array}{l}\text { Human density } \\
\text { (per sq km) }\end{array}$ \\
$23^{\circ} 51^{\prime}-25^{\circ} 00^{\prime}$ & 13,992 & 378 & 3 & 72 \\
$25^{\circ} 00^{\prime}-26^{\circ} 10^{\prime}$ & 7805 & 1215 & 16 & 67 \\
$26^{\circ} 10^{\prime}-27^{\circ} 00^{\prime}$ & 1577 & 415 & 26 & 38 \\
$27^{\circ} 00^{\prime}-28^{\circ} 23^{\prime}$ & 4607 & 1767 & 13 & 10 \\
Total (average) & 27,981 & 3776 & 13 & $(58)$ \\
\hline
\end{tabular}

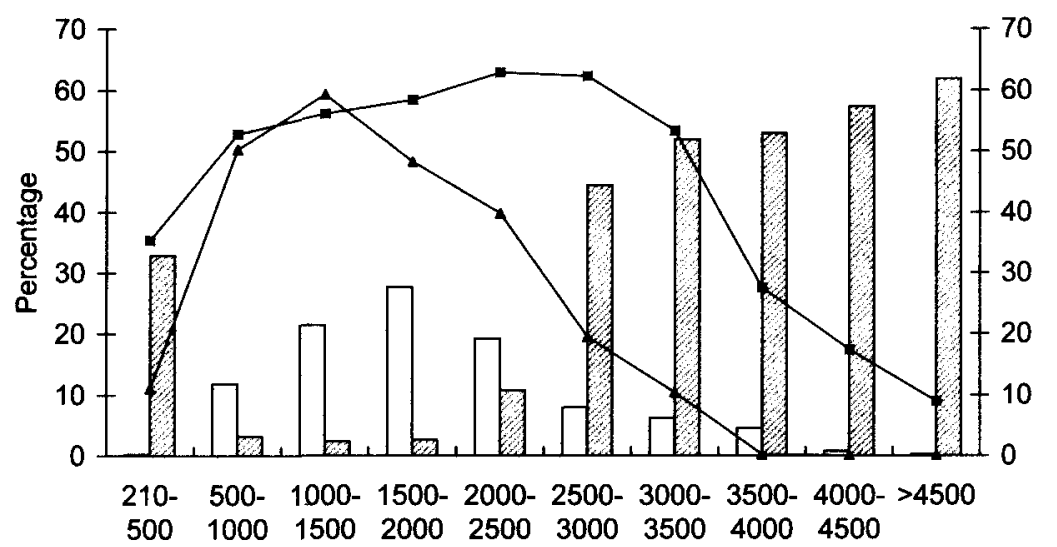

Altitude (m)

Fig. 2 Proportion of total land, land under reserve designation and species richness in elevational bands for Gaoligongshan Region. 
Fig. 3 Human population density and proportion of total land under reserve designation in elevational bands for Gaoligongshan Region.

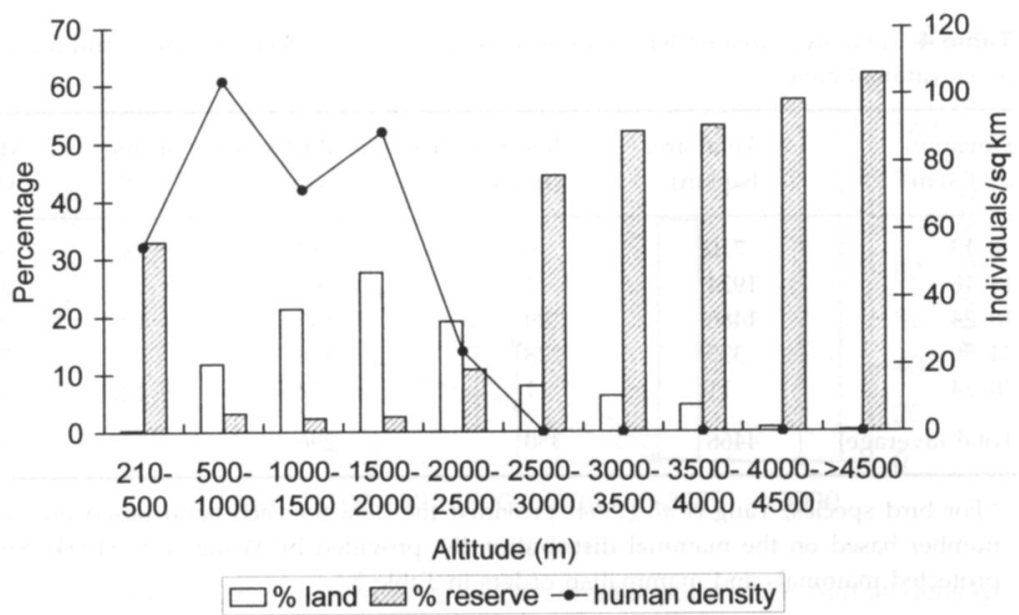

Patterns in species richness

Ninety-two per cent of all recorded mammal species inhabited the $1800-2400 \mathrm{~m}$ stratum; 50 per cent of recorded bird species appeared in the $2400-3000 \mathrm{~m}$ stratum. Eighty-two avian species (27.7 per cent) and 58 mammalian species (57.4 per cent) were recorded in the lowest elevational band $(800-1300 \mathrm{~m})$, despite the fact that this band accounted for less than 15.9 per cent of the region's total area. Species richness in the highest elevations appeared to be similar to the proportion of land surface area.

For both birds and mammals, the elevational pattern suggested a similar underlying pattern: species richness tended to be higher in the mid to high altitudinal zones, and lower in the areas of highest human density (the $1300-1800 \mathrm{~m}$ stratum). Considering the overall trends, these results differ from those for the topographically similar Gaoligongshan Region and Nepal, where species richness tends to be higher in tropical or hot low-altitudinal zones (Hunter \& Yonzon, 1993).

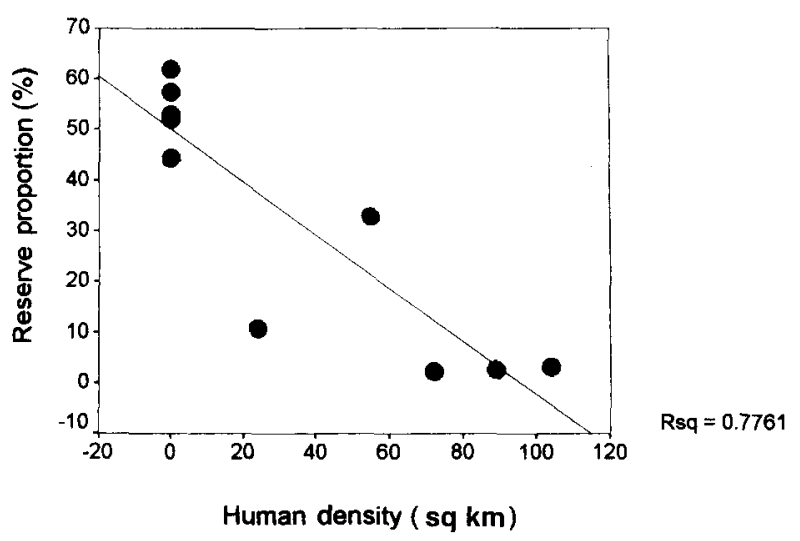

Fig. 4 Linear regression of reserve area on human density in Gaoligongshan Region. 
Table 4 Total area, area under nature reserve designation, species richness, and human population density in Jingdong County, stratified by elevational band

\begin{tabular}{lccccc}
\hline $\begin{array}{l}\text { Elevation } \\
(\times 100 \mathrm{~m})\end{array}$ & $\begin{array}{l}\text { Total area } \\
(\mathrm{sq} \mathrm{km})\end{array}$ & $\begin{array}{l}\text { Reserve area } \\
(\mathrm{sq} \mathrm{km})\end{array}$ & $\begin{array}{l}\text { Bird species* in the } \\
\text { whole area }\end{array}$ & $\begin{array}{l}\text { Mammal species* in the } \\
\text { whole area }\end{array}$ & $\begin{array}{l}\text { Human density } \\
\text { (per sq km) }\end{array}$ \\
\hline $8-13$ & 710 & 0 & 82 & 58 & 158 \\
$13-18$ & 1924 & 2 & 98 & 43 & 72 \\
$18-24$ & 1486 & 109 & 145 & 93 & 51 \\
$24-30$ & 335 & 228 & 148 & 19 & 1.6 \\
$30-34$ & 11 & 11 & 32 & 101 & $(73)$ \\
\hline
\end{tabular}

* For bird species, Yang et al. (1994) provided the data for each band based on the habitats; for mammals, we calculated the species number based on the mammal distribution list provided by Wang et al. (1994). Similar methods were used in the calculation of the protected mammals and mammalian orders in Table 5.

Table 5 Human population, protected species numbers and species of three mammal orders in Jingdong County, stratified by elevational band

\begin{tabular}{rrrrrrr}
\hline $\begin{array}{l}\text { Elevation } \\
(\times 100 \mathrm{~m})\end{array}$ & Total population & $\begin{array}{l}\text { Number of protected } \\
\text { bird species* }\end{array}$ & $\begin{array}{l}\text { Number of protected } \\
\text { mammal species* }\end{array}$ & Primates & Carnivores & Artiodactyla \\
\hline $8-13$ & 112,180 & 11 & 8 & 3 & 19 & 1 \\
$13-18$ & 138,528 & 7 & 3 & 7 & 7 & 2 \\
$18-24$ & 75,786 & 19 & 22 & 6 & 22 & 7 \\
$24-30$ & 536 & 11 & 23 & 0 & 7 & 3 \\
$30-34$ & 0 & 1 & 6 & 7 & 25 & 7 \\
Total & 327,030 & 30 & 25 & & & 7 \\
\hline
\end{tabular}

* Protected by law in China (source: Wang et al., 1994; Yang et al., 1994).

Note: The total corresponds to the number of species in the whole region; it is not the sum of each elevational band because the same species can occur at several elevational bands.

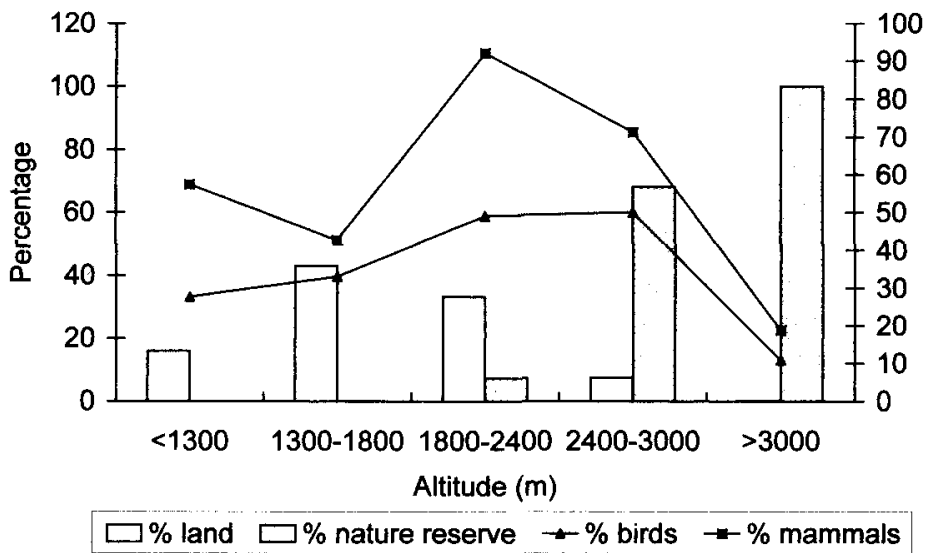

Fig. 5 Proportion of total land, land under reserve designation and species richness in elevational bands for Jingdong County.

\section{Reserve location}

How well did existing reserves in Jingdong County correspond with the patterns of species richness? Although the trends are not as clear as those for Gaoligongshan Region, the proportion of total land in reserves nevertheless showed negative, rather than positive, correlation with mammalian species richness (Fig. 5: $r=-0.200, P=0.747)$, although without statistical significance. Stratified by elevation, the proportion of land in reserves was negatively correlated with protected bird species numbers $(r=-0.359, P=0.553)$ (but not with bird species richness), as well as with numbers of primates $(r=-0.359, P=0.553)$ and carnivores $(r=-0.2, P=0.747)$. Positive correlations were found for artiodactyl species $(r=0.667, P=0.219)$ and protected mammal species $(r=0.2, P=0.747)$. In this 
Fig. 6 Human population, human population density and proportion of total land under reserve designation in elevational bands for Jingdong County.

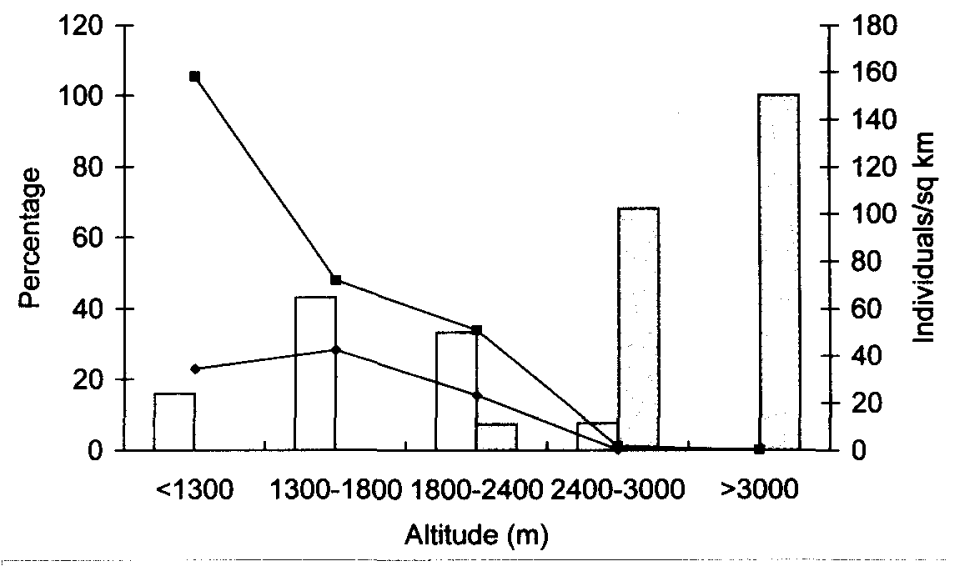

$\%$ land $\square \%$ nature reserve $\rightarrow-\%$ human population $\rightarrow$ - human density case, we cannot conclude that the areas with highest species richness (and numbers of protected species) correspond with the least nominally protected land.

As in the case of Gaoligongshan Region, we found that reserves were established where human population density was lowest. Stratified by elevation, the proportion of land in reserves was significantly negatively correlated with human population $(r=-0.9$, $P=0.037)$ and human population density $(r=-1.00$, $P<0.0001$ ) (Fig. 6).

The linear regression equation suggests that the nature reserves have not been (and perhaps cannot be) established where human density exceeds $118 / \mathrm{sq} \mathrm{km}$ (Fig. 7). Only in regions with a density less than 74/ $\mathrm{sq} \mathrm{km}$ and $30 / \mathrm{sq} \mathrm{km}$ did the reserve area exceed a quarter or half, respectively, of the total land area. These areas are larger than those for Gaoligongshan Region.

\section{Discussion}

\section{Nature reserve designation}

This analysis of Gaoligongshan Region and Jingdong County makes clear one important point, which is self-evident upon reflection: nature reserves have been placed where conflicts with humans are lowest, while areas where human density is highest are avoided. For Gaoligongshan Region, the results also demonstrate that species diversity is generally highest in the lower elevation sections (where crop cultivation is most productive) and lowest in the highest elevation sections (where humans can subsist on livestock only, which necessarily has a low density because of low primary productivity). Because species richness responds to the same fundamental factors as human density, the inevitable result is that nature reserves are placed where, from a species richness perspective, they are needed least.

Recent surveys (for example, Ma et al., 1994) have found that human disturbance is becoming more serious in those elevational bands with higher biodiversity (i.e. low-altitudinal bands). These activities include forest exploitation (commercial logging), cultivation by local shifting agriculture and cash-crop plantation (in some cases, valleys inside forest are exploited for their damp and shaded conditions). It should be noted here that the seemingly high level of protection afforded Gaoligongshan lands under $500-\mathrm{m}$ elevation is misleading: although nominally under reserve protection, recent surveys (Ma et al., 1994) have revealed a large influx of agriculturalists and frontier traders, and most original forest has now been replaced by cropland, highways and built-up areas, because it borders Myanmar and has a suitable climate for plantations. Moreover, a number of endangered bird and mammal species have disappeared from this area in the past 40 years or so (Ma et al., 1994), including hornbills and

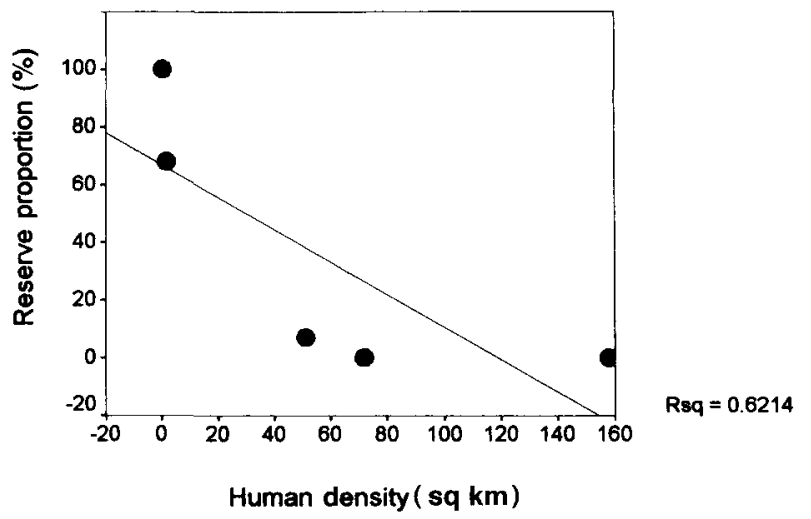

Fig. 7 Linear regression of reserve area on human density in Jingdong County. 
hoolock gibbons. Conflict of interest between local people, government and conservation staff occurs from time to time (Ma et al., 1994). However, although we can expect many wildlife populations in low altitude habitats to have been extirpated due to these increasing conflicts with the growing human population, there are insufficient data from recent surveys to allow us to determine the exact number of local extinctions.

In the case of Jingdong County, the results do not confirm that the tropical areas are of greater biodiversity. However, this may be because the collection of specimens in low altitude areas is not as good as in the high areas (usually from 1800 to $2800 \mathrm{~m}$ a.s.1. where good forest remains). Most primary habitat in low elevations had been altered by human activities long before any surveys were conducted. The lower the elevation, the more disturbance there is from humans and the greater the amount of habitat that is destroyed. Another reason for the low species richness for land under $1300 \mathrm{~m}$ is that this zone represents a much smaller proportion of total land (16.9 per cent). If each county in Gaoligongshan Region was analysed in the same way as Jingdong County, the results might be similar. However, Gaoligongshan Region is not homogeneous, so the analysis would not be straightforward.

\section{Biodiversity conservation in Yunnan: the present situation}

The findings reported here should be seen not so much as a criticism of forestry or reserve officials, but as an acknowledgement of the pre-eminence in conservation activities of socio-economic over strictly biological considerations. Given the difficulties that existing reserves already face in protecting nature resources effectively (Ma et al., 1994), we can only assume that attempts to establish reserves in more densely populated areas (albeit, areas that might have more species richness) would encounter even greater resistance.

Following the economic reforms of the late 1970s, the Chinese economy expanded greatly. Much attention in the West has focused on the rapid economic growth of Chinese cities and the south-eastern portions of China. However, the more remote, rural regions, like most of Yunnan, have not been immune to these pressures: if anything, pressures here are more intense due to the sense of having been 'left behind' by the more prosperous coastal regions. Unfortunately, the most immediate source of wealth in Yunnan is the rapid liquidation of existing natural resources, particularly forests, and this has inevitably increased the burden on biodiversity conservation.

In Yunnan, biodiversity in 90 per cent of the land area that lacks formal protected status is in a precarious state.
There has been some progress in protecting forest habitats in some subregions. Some areas are being reforested or conserved for watershed protection and some relatively small patches of untouched forest remain beyond the protection of nature reserves in both national forests and collective forests. However, the general trend has been to simplify ecosystems, and to convert lowland forests to agriculture and upland forests to commercial production of wood. Conversions of formerly wild areas to commercial uses have been especially common in the lower elevation $(<1000 \mathrm{~m})$ sections, as well as at midelevations $(1000-2000 \mathrm{~m})$. In contrast, creating new nature reserves is almost impossible, because the central and provincial governments are no longer prepared to support new reserves due to insufficient revenues and possibly sensitivity to criticism. In addition, recent government hydroelectric schemes, like those in Mekong Valley, may pose a further threat to low altitude habitats in Yunnan.

Two important points emerge: (1) conservationists who are dissatisfied with the current location or extent of China's nature reserve system, and who instead propose prioritizations based on species characteristics, must be prepared to describe how such biologically based designations can be realized, given that, thus far, designations have responded primarily to human realities; and (2) with or without formal reserve designation, a little conservation in currently unprotected areas, particularly in the lower elevations, is likely to go a long way. Absolute protection may not be realistic in these areas, but the moderation of habitat alteration and hunting practices can help stave off the elimination of many species.

\section{Acknowledgements}

This work was initiated at the suggestion of Dr William Bleisch when a conservation survey project was conducted in Gaoligongshan Region (1992-94) by the Kunming Institute of Zoology. The fieldwork for the survey in Gaoligongshan Region was supported by the MacArthur Foundation, and the main workers were Dr Shilai Ma, Dr Lianxian Han and Daoying Lan (DYL) and Dr Rich Harris (Wildlife Conservation Society). Many others also contributed to the survey. For the analysis of Jingdong County, data were collected by DYL during fieldwork on wild black gibbons [supported by the National Geographical Society (5845-97), the International Primatological Society and Primate Conservation, Inc.]. We sincerely thank Dr William Bleisch, Dr Harris, Dr Ma, Dr Han, DrWeizhi Ji and many others for their encouragement and support (including data, analysis and logistics) during DYL's stay in Yunnan. We would also like to thank WWF for providing DYL with a 
Russell E. Train Education for Nature Program Fellowship, which supplied his tuition fee and living expenses while he was conducting fieldwork in 1998. The paper was prepared for publication while DYL was in receipt of a Developing Countries Training Fellowship from the Wenner-Gren Foundation for Anthropological Research. We are indebted to the anonymous referees for their kind help in improving the manuscript.

\section{References}

Bird Group of Kunming Institute of Zoology (1980) Survey Report on Vertebrates in Gaoligongshan, vol. 2, Birds. Science Press, Beijing [in Chinese]

Committee of Annals Compiling of Jingdong County (1994) Annals of Jingtong County. Sichuan Dictionary Publication House, Chengdu [in Chinese].

Forest Resources Survey Team of Yunnan Province (1983) The Professional Survey Report of the Wuliangshan Nature Resere in Yunnan. Unpublished report, No. 5 Forest Resources Survey Team of Yunnan Provinces [in Chinese].

Forestry Planning and Surveying Institute of Yunnan Province (1989) Nature Reserves of Yunnan Province. China Forestry Press, Beijing [in Chinese].

Forestry Zonation Office of Jingdong County (1986) The Forest Resources of Jingdong Yi Autonomous County. Unpublished report, Jingdong Forestry Bureau, Jingdong [in Chinese].

Hunter, M.L. Jr. \& Yonzon, P. (1993) Altitudinal distributions of birds, mammals, people, forests, and parks in Nepal. Conserzation Biology, 7, 420-423.

Lan, D.Y. (1995a) Perspective on biodiversity conservation and economic development in Xiaobahe, Wuliang Mountain, Yunnan. In Advances in Biodiversity Research (eds Y. Q. Qian and R. D Zhen), pp. 93-98. Chinese Sciences and Technology Press, Beijing [in Chinese with English summary]

Lan, D.Y. (1995b) Distribution and conservation of black gibbons in Yunnan. In Research and Conservation of Primates (eds W. P. Xia and R. Z. Zhang), pp. 157-168. Chinese Forestry Publishing House, Beijing [in Chinese with English summary].

Lan, D.Y, Ma, S.L. \& Han, L.X. (1995) Distribution, numbers and conservation of hoolock gibbons in west Yunnan. In Study on the Mammal Biology in China (ed. J. Zhang), pp. 1-21. China Forestry Publishing House, Beijing [in Chinese with English abstract].

Li, W.H. \& Zhao, X.Y. (1989) China's Nature Reserves. Foreign Language Press, Beijing.

Liu, D.Y., Duan, H.Q., He, Y.W., Ren, J.C., Shi, W. Y., Wu, G.X., Chen, N.Z., Wang, W.M. \& Zhang, X.W. (1994) Scientific exploration on Wuliangshan Nature Reserve: comprehensive report. In The Survey Report of Wuliangshan Nature Reserve (ed. Wuliangshan Nature Reserve Management Bureau), pp. 1-16. Unpublished, Wuliangshan Nature Reserve Management Bureau, Jingdong [in Chinese].
Ma, S.L., Han, L.X. \& Lan, D.Y. (1994) Bird and Mammal Resources and Biological Conservation in the Gaoligongsitan Region. Final Report to the MacArthur Foundation. Unpublished report, Kunming Institute of Zoology, Kunming [in Chinese and English].

Ma, S.L., Han, L.X., Lan, D.Y., Ji, W.Z. \& Harris, R. (1995) Faunal resources of the Gaoligongshan Region of Yunnan, China: diverse and threatened. Environmental Conservation, 22, 250-258.

Ma, S.L., Han, L.X., Lan, D.Y, Ji, W.Z., Harris, R.\& \& Bleisch, W.B. (1997) Conservation and sustainable use of biodiversity in the multi-nationality inhabited area. In Conservation Biology (eds Z. G. Jiang, K. P. Ma and X. G. Han), pp. 219-224. Zhejiang Sciences and Technological Press, Hangzhou [in Chinese with English summary].

McNeely, J. (1990) Conserving the World's Biodiversity. Science and Technology Press, Beijing (1992) [in Chinese]. Chinese edition: chief translator W. J. Ma.

Peng, H. (1997) The endemism in the flora of seed plants in Mt. Wuliangshan. Acta Botanica Yunnanica, 19, 1-14 [in Chinese with English abstract].

Wang, Y.X. \& Wang, W.M. (1990) Report of investigation on mammals in Lushui, Gaoligongshan. Collections of Investigations on Gaoligongshan Nature Reserve (Lushui Part), Vol. 2 (ed. Gaoligongshan Nature Reserve Investigation Group), pp. 293-319. Unpublished, Bureau of Gaoligongshan Nature Reserve, Liuku [in Chinese].

Wang, Y.X., Jiang, X.L., Feng, Q. \& Chen, Z.P. (1994) The mammals of the Jingdong Wuliangshan Nature Reserve, Yunnan. In The Survey Report of Wuliangshan Nature Reserve (ed. Wuliangshan Nature Reserve Management Bureau), pp. 94-110. Unpublished report, Wuliangshan Nature Reserve Management Bureau, Jingdong [in Chinesel.

Wu, Z.Y., Zhang, J.Y. \& Li, C. (1979) The regionalization of Chinese flora. Acta Botanica Yunnanica, 1, 1-21 [in Chinese].

Wuliangshan Mountain Reserve Management Bureau (1994) The Survey Report of Wuliangshan Nature Reserve. Unpublished report, Wuliangshan Nature Reserve Management Bureau, Jingdong [in Chinese].

Yang, L, Wen, X.J. \& Yang, X.J. (1994) Survey and study of birds in Wuliangshan. In The Survey Report of Wuliangshan Nature Reserve (ed. Wuliangshan Nature Reserve Management Bureau), pp. 111-128. Unpublished report, Wuliangshan Nature Reserve Management Bureau, Jingdong [in Chinese].

Yunnan Mapping Bureau (1982) Map Collections of Yunnan Province. Kunming, Yunnan.

Zhang, Y.Z. (1979) The Physical Geography of China (Zoogeography). Science Press, Beijing [in Chinese].

Zhang, Y.Z. \& Lin, Y.L. (1985) The distribution tendency of land mammals in China and adjacent areas. Acta Zoologica Sinica, 31, 187-197 [in Chinese with English abstract].

Zheng, Z.X., Feng, Z.J., Zhang, Y.Z. \& Hu, S.Q. (1981) On the land-vertebrate fauna of Qinghai-Xizang Plateau with considerations concerning its history of transformation. Memoirs of Beijing Natural History Museum, 9, 1-21 [in Chinese]. 


\section{Biographical sketches}

Daoying Lan is a primatologist who has worked on behavioural ecology and conservation of wildlife in Yunnan, China for over 10 years; his current research focuses on the ecology of black gibbons. He has published in both Folia Primatologica and Biological Conservation.

Robin Dunbar is an evolutionary biologist whose interests include behavioural ecology and conservation. He has carried out fieldwork on primates and ungulates in Africa. His latest book, Primate Conservation Biology (co-authored with Guy Cowlishaw), will be published later in the year by Chicago University Press. 